\title{
Inhibition of cell proliferation, migration and invasion of B16-F10 melanoma cells by $\alpha$-mangostin
}

\author{
Simone Beninati ${ }^{a, *}$, Serafina Oliverio ${ }^{a}$, Martina Cordella ${ }^{b}$, Stefania Rossi ${ }^{c}$, Cinzia Senatore $^{c}$, \\ Immacolata Liguori ${ }^{\mathrm{a}}$, Alessandro Lentini ${ }^{\mathrm{a}}$, Lucia Piredda ${ }^{\mathrm{a}}$, Claudio Tabolacci ${ }^{\mathrm{a}, \mathrm{b}}$ \\ a Department of Biology, University “Tor Vergata”, Rome, Italy \\ ${ }^{\mathrm{b}}$ Department of Hematology, Oncology and Molecular Medicine, Istituto Superiore di Sanità, Rome, Italy \\ ${ }^{\mathrm{c}}$ Regina Elena National Cancer Institute, Rome, Italy
}

\section{A R T I C L E I N F O}

\section{Article history:}

Received 1 July 2014

Available online 11 July 2014

\section{Keywords:}

$\alpha$-Mangostin

Melanoma

Antimetastatic effects

Natural drugs

\begin{abstract}
A B S T R A C T
In this study, we have evaluated the potential antineoplastic effects of $\alpha$-mangostin $(\alpha-\mathrm{M})$, the most representative xanthone in Garcinia mangostana pericarp, on melanoma cell lines. This xanthone markedly inhibits the proliferation of high-metastatic B16-F10 melanoma cells. Furthermore, by deeply analyzing which steps in the metastatic process are influenced by xanthone it was observed that $\alpha$-M strongly interferes with homotypic aggregation, adhesion, plasticity and invasion ability of B16-F10 cells, probably by the observed reduction of metalloproteinase- 9 activity. The antiproliferative and antimetastatic properties of $\alpha$-M have been established in human SK-MEL-28 and A375 melanoma cells. In order to identify pathways potentially involved in the antineoplastic properties of $\alpha-\mathrm{M}$, a comparative mass spectrometry proteomic approach was employed. These findings may improve our understanding of the molecular mechanisms underlying the anti-cancer effects of $\alpha-\mathrm{M}$ on melanoma.
\end{abstract}

(ㄷ) 2014 Published by Elsevier Inc.

\section{Introduction}

Melanoma is the most aggressive form of skin cancer, and its incidence is increasing at a rate greater than any other form of cancer; further, it remains one of the most difficult cancers to treat [1]. Therefore, the development of effective therapy or at least as adjuvant of classical chemotherapy is still required. Mangosteen (Garcinia mangostana L.) is a tropical evergreen tree. Different parts of mangosteen, mainly fruits, bark and roots have been used for centuries in Southeast Asia [2]. The major bioactive secondary metabolites of $G$. mangostana are xanthone derivatives and they are present mostly in the pericarp of the fruit [3]. Xanthones is a class of polyphenolic compounds with a skeleton of a xanthene-9one [4]. The most studied xanthones are $\alpha-, \beta$ - and $\gamma$-mangostins, garcinone $\mathrm{E}$, mangostenones and gartanin. The antioxidant, antiinflammatory, antibacterial and antiviral activities of xanthones are described [5]. The antineoplastic activity of $\alpha$-mangostin ( $\alpha$-M; 1,3,6-trihydroxy-7-methoxy-2,8-diprenyl-9H-xanthen-9-one), the most representative xanthone in mangosteen pericarp (78\% content), has been established on human hepatoma [6], breast

\footnotetext{
* Corresponding author. Address: Department of Biology, University "Tor Vergata", Via della Ricerca Scientifica, 00133 Rome, Italy. Fax: +39 062023500. E-mail address: beninati@bio.uniroma2.it (S. Beninati).
}

cancer [7] and pancreatic cancer [8]. In particular $\alpha$-M was reported to have antitumor effects on human melanoma tumor cells previously [9]; however, the details of the mechanism remain unclear. Metastasis of cancer cells involves multistep processes and various cyto-physiological changes, including adhesion and invasion. Several lines of evidence suggest that tissue transglutaminase (TG; EC 2.3.2.13), an enzymes that modify proteins post-translationally in a calcium-dependent manner, leading to the formation of covalent $\varepsilon(\gamma$-glutamyl)lysine linkages, has a potential role in the various stages of the metastatic cascade [10]. The aim of this study was to elucidate the antineoplastic effects of $\alpha-\mathrm{M}$ on B16-F10 mouse melanoma cells, human SK-MEL-28 and A375 melanoma cells, to find new evidences on the various stages of metastatic process involved. In particular, the antimetastatic potential, the effects on cell proliferation and the possible induction of tumor cell differentiation exerted by $\alpha-\mathrm{M}$ have been investigated.

\section{Materials and methods}

\subsection{Cell line and reagents}

B16-F10 highly metastatic murine melanoma cells, SK-MEL-28 and A375 human melanoma cells were propagated under standard 
culture conditions. Dulbecco's Modified Eagle Medium (D-MEM), Roswell Park Memorial Institute medium (RPMI), Foetal Calf Serum (FCS) and all cell culture media were obtained from Gibco (Grand Island, NY, USA). $\left[{ }^{14} \mathrm{C}\right]$-methylamine $(46.6 \mathrm{mCi} / \mathrm{mmol})$ was purchased from Amersham International (Bucks, UK). Matrigel (MG), $\alpha-\mathrm{M}$, ethylenediaminetetraacetic acid (EDTA), synthetic melanin and all reagents were from Sigma Chemicals (St. Louis, MO, USA). Eight $\mu \mathrm{m}$-sized porous filters were purchased from Millipore S.p.A. (Milano, Italy).

\subsection{Cell cultures, proliferation studies and cell cycle analysis}

Melanoma cells were grown in D-MEM (B16-F10 and A375) or RPMI (SK-MEL-28) supplemented with 10\% FCS, 2 mM L-glutamine, $100 \mathrm{U} / \mathrm{ml}$ penicillin, and $100 \mu \mathrm{g} / \mathrm{mL}$ streptomycin. All cell cultures were incubated at $37{ }^{\circ} \mathrm{C}$ in a humidified atmosphere of $5 \% \mathrm{CO}_{2}$. For treatments, $\alpha-\mathrm{M}$ was dissolved in dimethylsulfoxide (DMSO). For proliferation assay, cells were seeded and grown in $35 \mathrm{~mm}$ dishes and treated with $\alpha$-M $(5,10$ and $15 \mu \mathrm{M})$ for $48 \mathrm{~h}$. Cells were harvested and counted with a Neubauer modified chamber. For cytotoxicity evaluation, cells were tested by the Trypan Blue $(0.25 \%)$ exclusion test. Cell cycle distribution was determined by flow cytometric analysis of propidium iodide-labelled cells as previously described [11].

\subsection{Evaluation of melanoma cell differentiation}

B16-F10 cells are a good model for melanoma differentiation. For melanin content evaluation, melanotic B16-F10 and lightly pigmented SK-MEL-28 cells were cultured in the presence of $\alpha$-M for $48 \mathrm{~h}$ then detached, washed twice in phosphate buffer saline and collected by centrifugation and counted. Melanin was extracted from cells with $1 \mathrm{ml}$ of $1 \mathrm{M} \mathrm{NaOH}$ at $60^{\circ} \mathrm{C}$ for $1 \mathrm{~h}$. Melanin content was determined by absorption at $475 \mathrm{~nm}$, using the standard curve obtained from a solution of synthetic melanin $(0-100 \mu \mathrm{g} / \mathrm{ml})$.

Transglutaminase (TG) activity assay was performed on B16-F10 cell lysates using $\left[{ }^{14} \mathrm{C}\right]$-methylamine $(46.6 \mathrm{mCi} / \mathrm{mmol})$ as substrate, as previously described [12]. Radiolabelled amine incorporation into cell proteins was measured with a scintillation counter (Beckman LS-5000TD, CA, USA).

Determination of intracellular protoporphyrin IX (PpIX) concentration was performed as previously described [13].

\subsection{Aggregation and adhesion assays}

For aggregation assay, melanoma cells were cultured in the presence of $\alpha-\mathrm{M}$ for $48 \mathrm{~h}$, then detached and resuspended in $0.1 \%$ bovine serum albumin (BSA) in D-MEM. Viable cells $\left(2 \times 10^{5}\right)$ were transferred into a 24-well culture plate. The plate was gently shaken at $37^{\circ} \mathrm{C}$ for $90 \mathrm{~min}$ and measurement of cell aggregates was determined under light microscope.

The adhesion assay was performed on 24-well plates coated with $10 \mu \mathrm{g} /$ well of MG by using a modified adhesion assay already published [14].

\subsection{Invasion assays and gelatin zymography}

For 3D invasion assay, cells $\left(4 \times 10^{5}\right)$ were mixed with an equal volume of MG and plated on a 12-well culture plate, and incubated for $4 \mathrm{~h}$ at $37^{\circ} \mathrm{C}$ to allow gel formation. After incubation, the number of cellular processes per cell was evaluated under light microscope.

Invasion assay was performed in a modified Boyden chamber as previously described [12] using NIH-3T3 murine fibroblastconditioned medium (for B16-F10) or FCS (SK-MEL-28 and A375) as chemoattractant. MG-coated filters were placed between the two compartments. Chambers were incubated in a humidified 5\% $\mathrm{CO}_{2}$ atmosphere for $6 \mathrm{~h}$ at $37^{\circ} \mathrm{C}$. The filter was fixed by $100 \%$ ethanol, stained with Giemsa solution (5\%). The number of invasive cells was evaluated by means of Image J software (National Institutes of Health, Bethesda, Maryland, USA; http://rsb.info.nih.gov/ $\mathrm{ij} /$ ) and results expressed as percentage with respect of the control (100\%).

Secretion of matrix metalloproteinase-9 (MMP-9) from $\alpha$-Mtreated cells was analyzed by gelatin zymography according to a published method [15].

\subsection{Mass spectrometry and protein identification}

Gel-based proteome analysis of $\alpha$-M-treated B16-F10 cells was performed. Cell lysates were prepared as previously described [16]. Proteins from collected cells were run in a $4-15 \%$ Mini-PROTEAN ${ }^{\circledR}$ $\mathrm{TGX}^{\mathrm{TM}}$ pre-cast polyacrylamide gel (Bio-Rad Laboratories, Hercules, CA). For protein identification, the total gel lane was cut, proteins were reduced, alkylated and digested overnight with bovine trypsin sequencing grade (Roche Applied Science, Monza, IT). The peptide mixtures were analyzed by nano-reversed-phase liquid chromatography tandem mass spectrometry (RP-LC-MS/MS) using an HPLC Ultimate 3000 (DIONEX, Sunnyvale, CA) connected on line with a linear Ion Trap (LTQ, ThermoElectron, San Jose, CA). Peptides were desalted in a trap column (Acclaim PepMap 100 C18, LC Packings, DIONEX) and then separated in a reverse phase column, a $10 \mathrm{~cm}$ long fused silica capillary (Silica Tips FS 360-75-8, New Objective, Woburn, MA), slurry-packed in-house with $5 \mu \mathrm{m}$, 200 Å pore size C18 resin (Michrom BioResources, CA). Data acquisition and analysis was performed as previously described [16-17]. Data were searched with 1.5 Da and 1 Da tolerance respectively for precursor and fragment ions. A peptide was considered legitimately identified when it achieved cross correlation scores of 1.5 for $[\mathrm{M}+\mathrm{H}] 1+, 2.0$ for $[\mathrm{M}+2 \mathrm{H}] 2+, 2.5$ for $[\mathrm{M}+3 \mathrm{H}] 3+$, and a peptide probability cut-off for randomized identification of $p<0.001$.

\subsection{Bioinformatics analysis}

Unique proteins identified by proteomic analysis were further analyzed by The Database for Annotation, Visualization and Integrated Discovery (DAVID, ver 6.7) software (http://david.abcc. ncifcrf.gov/). DAVID provides a comprehensive set of functional annotation tools for investigators to understand biological meaning behind a large list of proteins [18]. DAVID functional annotation cluster analysis was performed on the list of proteins of B16-F10 control cells and treated with $15 \mu \mathrm{M} \alpha$-M for $48 \mathrm{~h}$. Only those terms with a $p$-value $\leqslant 0.005$ were selected for DAVID analysis. The Gene Ontology (GO) terms of biological process and SP_PIR_Keywords in the Functional Categories section in DAVID were used.

\subsection{Statistical analysis}

All data represented at least three independent experiments and were expressed as mean \pm S.D., unless otherwise indicated. Statistical comparisons were made using two tail Student's $t$-test. $p$-values of 0.05 or less were considered to represent a statistically significant difference.

\section{Results}

\subsection{Effects of $\alpha-M$ on melanoma cell proliferation}

In this study, we first assayed the antiproliferative effects of $\alpha-\mathrm{M}$ on B16-F10 for $48 \mathrm{~h}$. As shown in Fig. 1A, $\alpha-\mathrm{M}$ revealed dose-dependent inhibitory effect on the growth of melanoma cells. 
A

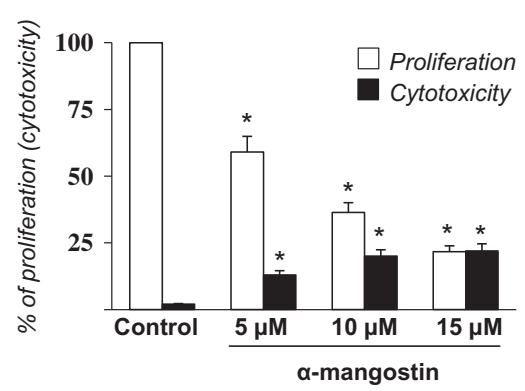

B
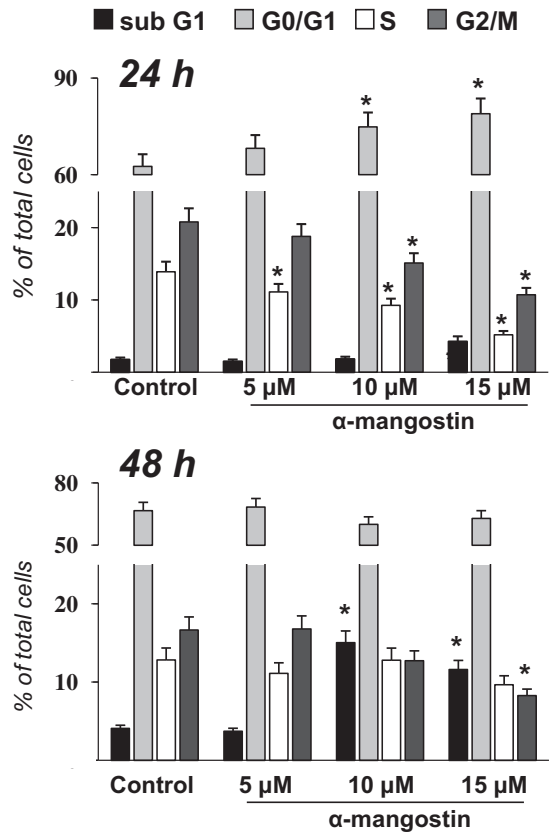

C
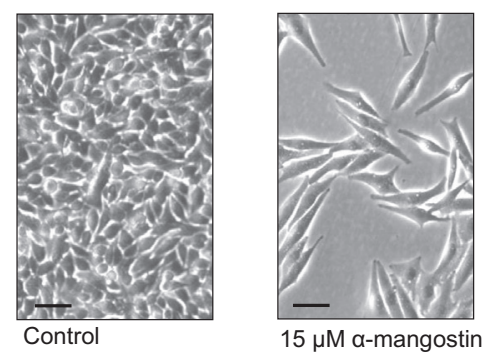

Fig. 1. Effects of $\alpha$-mangostin ( $\alpha-M)$ on proliferation, cell cycle and morphology of B16-F10 melanoma cells. (A) $\alpha$-M reduces the growth of B16-F10 melanoma cells (white bar). Cytotoxic effects, evaluated by Trypan blue dye exclusion assay, of $\alpha-\mathrm{M}$ on B16-F10 cells are also shown (black bars). (B) Cell cycle analysis of B16-F10 cells untreated or treated with $5 \mu \mathrm{M}, 10 \mu \mathrm{M}$ and $15 \mu \mathrm{M} \alpha-\mathrm{M}$ for 24 , and $48 \mathrm{~h}$. Flow cytometric analysis of the cellular DNA content was performed after propidium iodide staining, and the subG0/G1 region represents the apoptotic cell population. (C) Light microscopical appearance of untreated and $15 \mu \mathrm{M} \alpha$-M-treated B16-F10 melanoma cells after $48 \mathrm{~h}$ of exposure (original magnification: $200 \times$ ). The data are presented as mean \pm SD from representative of three independent experiments (statistical significance: ${ }^{*} p<0.05,{ }^{\#} p<0.01$, refers to untreated cultures). Scale bar: $20 \mu \mathrm{m}$.

Compared to the control, cells treated with 5, 10 and $15 \mu \mathrm{M} \alpha-\mathrm{M}$, showed a significant decrease of cell proliferation (by $40.9 \%$, $63.6 \%$ and $78.3 \%$ respectively). Moreover, as illustrated in Fig. 1B, $\alpha$-M showed slight cytotoxic effects, not exceeding the $25 \%$. Similar results were obtained in SK-MEL-28 and A375 melanoma cells (Table 1). For these cells, proliferation was reduced by $32.3 \%$ in SK-MEL-28 and by $45.5 \%$ in A375 cells after 48 h.

\subsection{Effects on cell cycle}

In order to elucidate the inhibition mode of B16-F10 cell growth by $\alpha-\mathrm{M}$, we measured DNA content using flow-cytometry after PI staining of nuclei. As shown in Fig. 1B, the proportion of subG0/ G1 cell population increased after $\alpha$-M exposure, especially at $15 \mu \mathrm{M}$ treatment. A slight increase in G0/G1 phase has been observed after $24 \mathrm{~h}$ of drug exposure.

\subsection{Induction of melanoma cell differentiation after $\alpha-M$ treatment}

We investigated the potential effects of $\alpha$-M on the differentiation of B16 cells. As shown in Table 2, treatment of B16-F10 with $15 \mu \mathrm{M} \alpha-\mathrm{M}$ increased the amount of melanin, with respect to the control, by about 2-fold. Similar results were found for TG activity.

Increase of intracellular PpIX, a compound synthesized during heme biosynthesis, is considered a differentiation marker [19]. The effect of $\alpha-\mathrm{M}$ on intracellular accumulation of PpIX in B16F10 cells is shown in Table 2, where the concentration of intracellular PpIX significantly increased by $66.2 \%$ and $77.9 \%$ in 10 and $15 \mu \mathrm{M} \alpha$-M-treated cells respectively.

The induction of differentiation in $15 \mu \mathrm{M} \alpha$-M-treated cells was confirmed by light microscopic observations. As known, cytoplasmic protrusions are recognized as a morphological indicator of melanocyte/melanoma cell differentiation. Indeed, the morphology of B16-F10 cells incubated with $15 \mu \mathrm{M} \alpha$-M was markedly changed with respect to the control (Fig. 1C). No differences in morphology and in melanin content (SK-MEL-28) were found in human melanoma cells (data not shown).

\section{4. $\alpha$-M strongly interferes with metastatic potential of melanoma cells}

Loss of tumor cell homotypic aggregation represents one of the early steps of the metastatic spread. To determine whether $\alpha-\mathrm{M}$ would affect the cell-cell adherence behavior of B16-F10, cell aggregation assay was performed. We found that $\alpha$-M significantly increased the ability of B16 cells to form cell aggregates (Fig. 2A and $B$ ). In particular, $\alpha-M$ treatment enhanced the amount of cell aggregates in a dose-dependent manner (by about 3-fold after $15 \mu \mathrm{M} \alpha-\mathrm{M}$ treatment). The interaction of tumor cells with basement membrane proteins plays a pivotal role in tumor cell metastatization. Fig. 2B illustrates also the adhesion pattern of B16-F10 cells over MG-coated substrates. As shown, xanthone reduces, with respect to the control, the adhesion pattern of cells, by $31.5 \%$ and $88.8 \%$ after 10 and $15 \mu \mathrm{M} \alpha$-M. The reduction of the plasticity in $\alpha$-M-treated cells was established by the 3D-invasion assay. B16F10 cells responded to $\alpha$-M incubation in a dose-dependent manner by markedly reducing the branching-process formation (Fig. 2C and D). Next, we examined the invasive potential of B16 cells. The number of treated cells that were able to cross the MGcoated membrane was reduced by the administration of $\alpha$-M at several concentrations. The reduction of invasion obtained following treatment of 5,10 and $15 \mu \mathrm{M} \alpha-\mathrm{M}$ was of $57.2 \%, 64.2 \%$ and 79.6\% respectively (Fig. 2D and E).

MMP-9 is involved in extracellular matrix degradation and in several types of human cancers, its expression is abnormally elevated and has been associated with poor prognosis [20]. The evaluation of the integrated optical density of MMP-9 showed that its activity was reduced, with respect to the control, by about $59 \%$ and $63 \%$ after 10 and $15 \mu \mathrm{M} \alpha$-M treatments respectively (Fig. $2 \mathrm{~F}$ ).

Table 1 illustrates the adhesion and invasion patterns of SKMEL-28 and A375 cells. As shown, $15 \mu \mathrm{M} \alpha$-M reduces significantly, with respect to the control, the adhesion in A375 cells (by about $70 \%$ ). The invasion was reducing in both cell lines by $38 \%$ and $28 \%$ in SK-MEL-28 and A375 cells, respectively. 
Table 1

Effects of $\alpha$-M on proliferation, adhesion and invasion abilities of human SK-MEL-28 and A375 melanoma cells.

\begin{tabular}{llll}
\hline Group & $\begin{array}{l}\text { Proliferation } \\
(\%)\end{array}$ & $\begin{array}{l}\text { Adhesion } \\
(\%)\end{array}$ & $\begin{array}{l}\text { Invasion } \\
(\%)\end{array}$ \\
\hline $\begin{array}{l}\text { B16-F10/SK-MEL-28/A375 } \\
\quad(\text { Control })\end{array}$ & 100 & 100 & 100 \\
B16-F10 $(15 \mu \mathrm{M} \alpha-\mathrm{M})$ & $21.7 \pm 2.2^{\mathrm{a}}$ & $11.2 \pm 1.3^{\mathrm{b}}$ & $20.4 \pm 1.9^{\mathrm{a}}$ \\
SK-MEL-28 $(15 \mu \mathrm{M} \alpha-\mathrm{M})$ & $67.8 \pm 12.8^{\mathrm{a}}$ & $86.5 \pm 9.1$ & $62.3 \pm 13.7^{\mathrm{c}}$ \\
A375 $(15 \mu \mathrm{M} \alpha-\mathrm{M})$ & $54.5 \pm 2.3^{\mathrm{a}}$ & $30.2 \pm 9.9^{\mathrm{c}}$ & $71.9 \pm 19.7^{\mathrm{b}}$ \\
\hline
\end{tabular}

Data are mean \pm SD from three independent determinations.

a $p<0.05$.

b $p<0.01$.

c $p<0.005$ were considered to be statistically significant (vs control group).

Table 2

Effect of $\alpha$-M on melanin content, transglutaminase (TG) activity and protoporphyrin IX (PpIX) accumulation in B16-F10 cells.

\begin{tabular}{|c|c|c|c|}
\hline & Melanin content ( $\mu \mathrm{g}$ melanin $/ 10^{6}$ cells) & TG activity (\%) & PpIX accumulation (a.u. fluorescence/mg protein) \\
\hline Control & $1.52 \pm 0.51$ & 100 & $3.58 \pm 0.39$ \\
\hline $5 \mu \mathrm{M} \alpha-\mathrm{M}$ & $1.83 \pm 0.58$ & $93.5 \pm 14.3$ & $4.58 \pm 0.62$ \\
\hline $10 \mu \mathrm{M} \alpha-\mathrm{M}$ & $2.01 \pm 0.46$ & $94.1 \pm 14.1$ & $5.95 \pm 0.65^{\mathrm{a}}$ \\
\hline $15 \mu \mathrm{M} \alpha-\mathrm{M}$ & $3.25 \pm 0.72^{\mathrm{a}}$ & $223.5 \pm 20.5^{\mathrm{a}}$ & $6.37 \pm 0.87^{\mathrm{a}}$ \\
\hline
\end{tabular}

TG activity in control cells was $1280 \mathrm{CPM} / \mathrm{mg}$ protein. Data are mean \pm SD from three independent determinations.

${ }^{a} p<0.05$ was considered to be statistically significant.

A

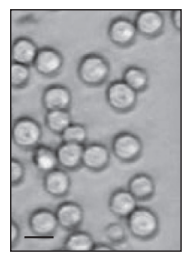

Control

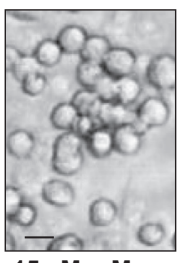

$15 \mu \mathrm{M} \alpha-\mathrm{M}$
C

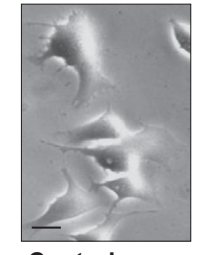

Control

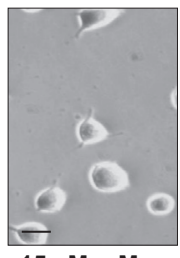

$15 \mu \mathrm{M} \alpha-\mathrm{M}$
E
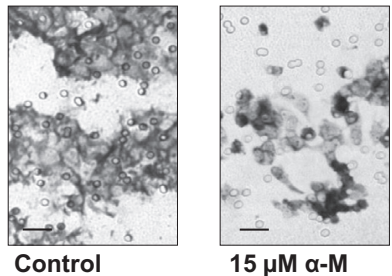

$15 \mu \mathrm{M} \alpha-\mathrm{M}$
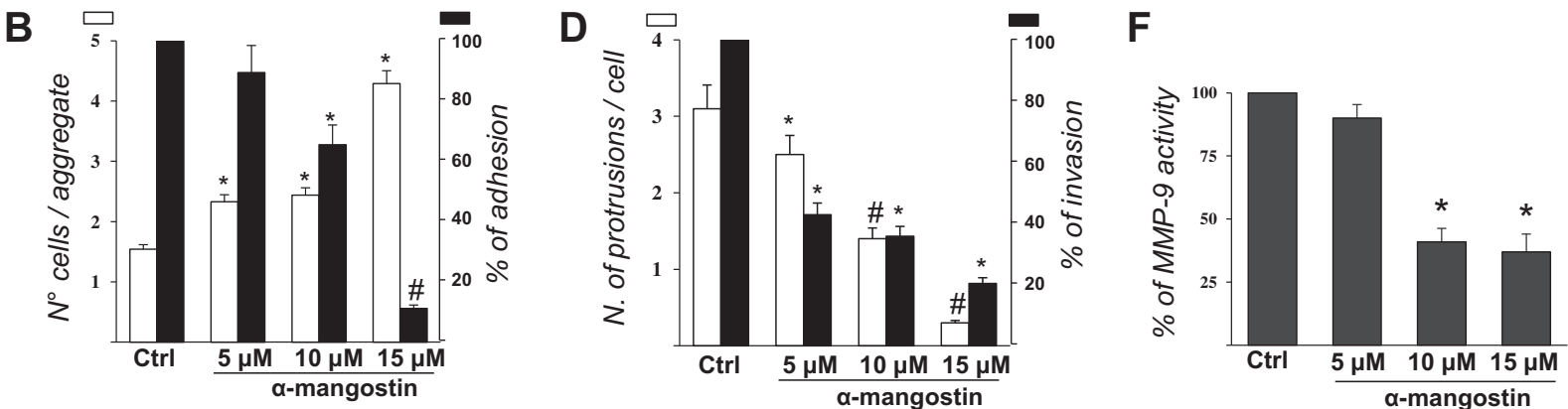

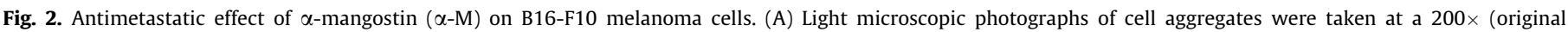

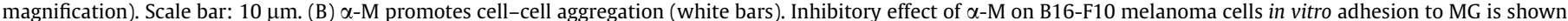

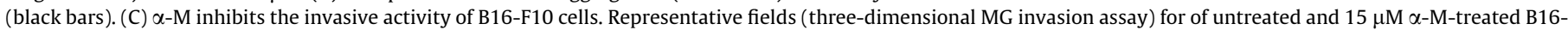

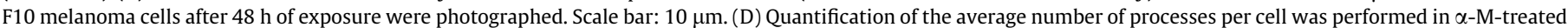

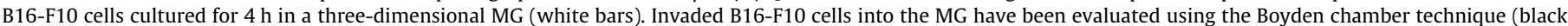

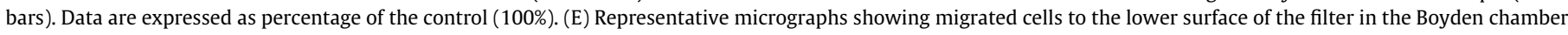

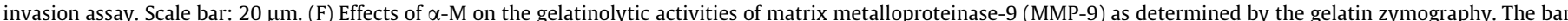

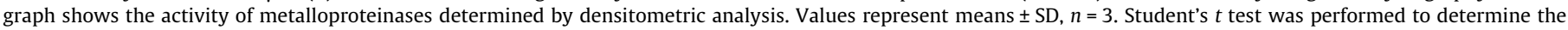
significance $\left({ }^{*} p<0.05\right.$ and $\left.{ }^{\#} p<0.01\right)$.

\subsection{Functional analysis of B16-F10 proteome after $\alpha-M$ treatment}

With the aim of improving the understanding of anti-cancer molecular mechanisms of $\alpha$-M on melanoma cells we carried out a gel-based mass spectrometry analysis of the proteome of the treated B16-F10 cell line and data were compared with the control (Supplementary Table 1).

As shown in Fig. 3A, 569 proteins were common for both groups, 154 proteins were found only in control cells and 140 proteins in $\alpha$-M-treated cells. The unique proteins were characterized by DAVID according to their biological processes and molecular function. As shown in pie charts, cell cycle (in control cells) and cytoskeleton and cellular component reorganization (in treated cells) are the discriminating biological processes between the two data sets of unique proteins (Fig. 3B). Performing functional annotation cluster by DAVID in the same data set, functions associated with endoplasmic reticulum (ER) and Golgi regulation, ubiquitination, actin binding, protein biosynthesis, GTP-binding and 
A

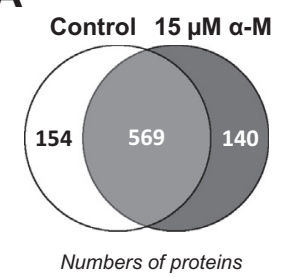

B

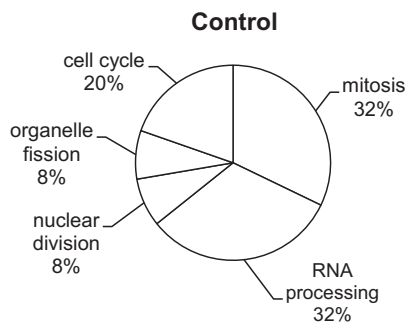

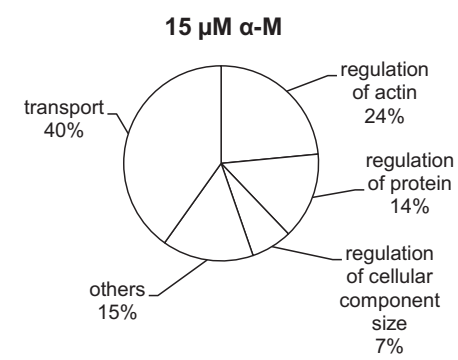

$15 \mu \mathrm{M} \alpha-\mathrm{M}$
C

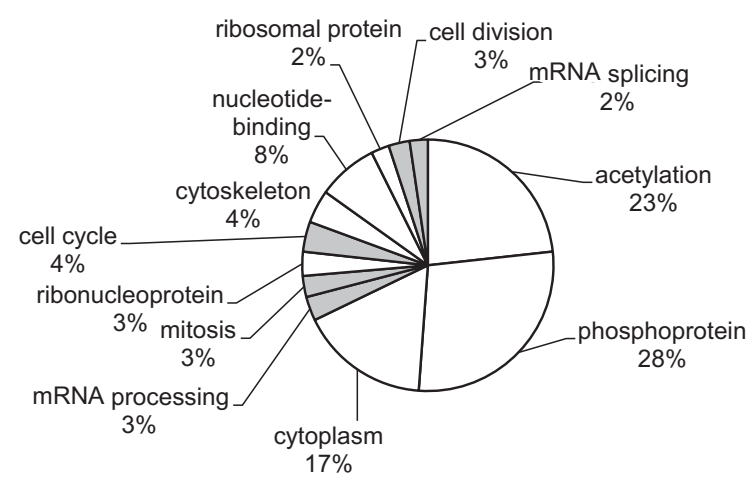

Control

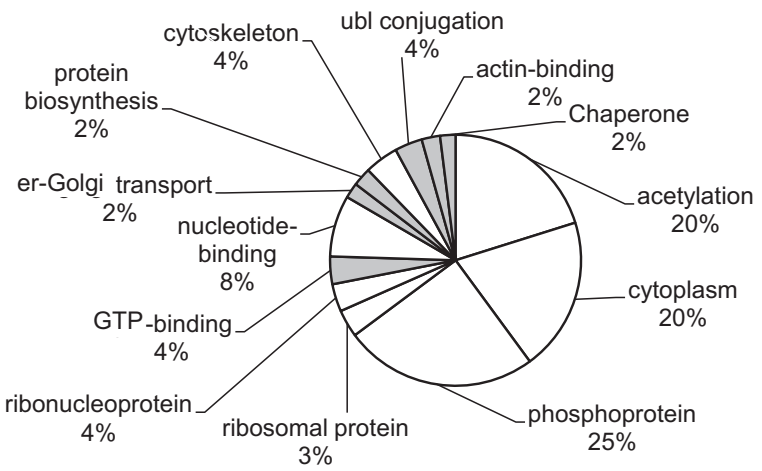

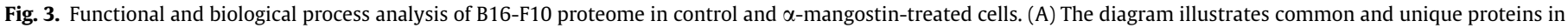
melanoma cells with or without $\alpha$-mangostin. DAVID classification of proteins based on (B) biological processes and (C) molecular functions.

chaperon were enriched in treated cells. On the contrary, as expected, functions related to cell cycle and mRNA regulation were found in normal-proliferating untreated cells (Fig. 3C).

\section{Discussion}

During the last years, great attention has been given to a variety of dietary substances for treatment and prevention of cancer [21]. It has been suggested that many of these compounds (such as resveratrol, $\beta$-carotene and vitamin A), due to their antioxidant properties, may contrast the ultraviolet light induced oxidative skin damage [22]. Therefore dietary factors with antioxidant properties have been proposed for prevention and treatment of many cancers and in particular of melanoma [23]. Besides polyphenols, it has been demonstrated that xanthones exhibit a potent antioxidant activity. Many of naturally occurring xanthones are found in the pericarp of G. mangostana L. [5].

In the present work, we provide evidence that $\alpha-M$, the most representative xanthone in mangosteen pericarp, decreases proliferation and viability of B16-F10 melanoma cells in various ways, including differentiation and induction of apoptosis. A promising approach to the treatment of cancer involves the induction of the terminal differentiation and growth arrest of cancer cells [24]. Melanoma is well known as a chemotherapy-resistant cancer, and it has been suggested that melanoma might be a suitable target for therapy with differentiation-inducing agents [21]. The induction of functional differentiation in B16-F10 melanoma cells occurs mainly after $15 \mu \mathrm{M} \alpha$-M treatment. In fact an increase in the activity of TG, a marker of terminal differentiation [25], in melanin synthesis and in PpIX accumulation, was observed. However, the effects of xanthones from mangosteen on melanogenesis seem controversial. Hamid and colleagues [26] have demonstrated the melanogenic potential of mangosteen leaf extract in B16-F1 melanoma cells. Conversely, mangostenone $\mathrm{F}$ was found to inhibit melanin production [27]. Since terminal differentiation is a part of apoptotic process [28] we also investigate the effect of $\alpha$-M on cell cycle distribution. We found that $\alpha-\mathrm{M}$ first arrests B16 cells in G0/ G1 phase ( $24 \mathrm{~h}$ ) and thereafter induces an increase in subG1 cell population $(48 \mathrm{~h})$. An additional observable parameter of melanoma cell differentiation is morphological change [29]. B16-F10 cells are usually polygonal but extension of dendritic processes is observed after induction of differentiation [30]. Surprisingly, cells treated with $\alpha$-M displayed a non-classical differentiate phenotype and acquired an elongated morphology, hence this absence of a marked dendritogenesis requires further investigations. In the present study, we observed also that $\alpha-\mathrm{M}$ has a strong antimetastatic potential, as shown by the reduction of homotypic aggregation, adhesion, shape fickleness and invasion of B16-F10 melanoma cells. This suggests the possibility to use $\alpha-\mathrm{M}$ as new interesting drug to interfere with the complex balance among extra-cellular matrix components, angiogenesis and tumor cells adhesions, as suggested [14]. These data might depend, relatively to that observed for the highest dose of $\alpha-\mathrm{M}$, on the activation of the transamidating form of TG [10]. As last evidence, we observed that $\alpha$-M is able to induce a reduction of MMP-9 activity, considered a prognostic marker in some human tumours [31]. Moreover, it has been demonstrated that TG inhibits significantly MMP-9 activity and expression [32]. The antimetastatic potential of $\alpha$-M was established also in two human melanoma cell lines. In particular, we observed a marked reduction of the adhesion of A375 following treatment with $\alpha-\mathrm{M}$. Our data confirmed the antimetastatic effects of $\boldsymbol{\alpha}-\mathrm{M}$ on melanoma cells as previously reported [9]. Both human cell lines, while showing signs of reduction of malignancy, do not seem to differentiate.

The functional and metabolic differences between control and $15 \mu \mathrm{M} \alpha$-M-treated B16 cells were investigated by proteomic analysis. The data revealed that in untreated cells there is a major prevalence of protein involved in cell cycle progression, as expected in proliferating cells. On the contrary, we found that $\alpha$-M promote the induction of protein involved in cellular reorganization, probably after the induction of terminal differentiation and apoptosis. Interestingly, DAVID analysis of unique proteins revealed a possible correlation between functional categories found in $\alpha$-M-treated B16 
cells and TG. In fact, TG is a multifunctional enzyme with both protein cross-linking (transamidating) and GTP-hydrolyzing and -binding activities [33]. Moreover, GTP binding is crucial for transamidating activity of tissue TG [34]. The presence of proteins related to cytoskeleton and actin (well-known substrate of TG) reorganization, from a part might explain the differences in cellular morphology and on the other hand might elucidate the progression of apoptosis and the inhibition of cellular plasticity and invasion [35]. The potential role of TG in the Golgi and vesicles network is also known [36]. Although randomized controlled trials of human participants are lacking, basic science and epidemiologic studies both show promising benefits of many natural products in chemoprevention for melanoma through dietary nutrients.

\section{Disclosure of interest}

The authors declare that they have no conflicts of interest concerning this article.

\section{Acknowledgments}

Tabolacci C. was a FILAS-Regione Lazio fellow. The support from Fondazione Umberto Veronesi to Tabolacci C. is also acknowledged. The technology support from the Facility for Complex Protein Mixture (CPM) Analysis at ISS (Rome), the financial support from Italy-USA Oncoproteomic Program and Telethon-Italy (Grant GTF08002) and the critical reading of the manuscript from Dr. F. Facchiano are kindly acknowledged. Cordella M. was a recipient of a ISS-Sapienza University Ph.D. fellow.

\section{Appendix A. Supplementary data}

Supplementary data associated with this article can be found, in the online version, at http://dx.doi.org/10.1016/j.bbrc.2014.07.031.

\section{References}

[1] E.M. Dunki-Jacobs, G.G. Callender, K.M. McMasters, Current management of melanoma, Curr. Probl. Surg. 50 (2013) 351-382.

[2] D. Obolskiy, I. Pischel, N. Siriwatanametanon, M. Heinrich, Garcinia mangostana L.: a phytochemical and pharmacological review, Phytother. Res. 23 (2009) 1047-1065.

[3] H.A. Jung, B.N. Su, W.J. Keller, R.G. Mehta, D. Kinghorn, Antioxidant xanthones from pericarp of Garcinia mangostana (Mangosteen), J. Agric. Food. Chem. 54 (2006) 2077-2082.

[4] M.M. Pinto, M.E. Sousa, M.S. Nascimento, Xanthone derivatives: new insights in biological activities, Curr. Med. Chem. 12 (2005) 2517-2538.

[5] T. Shan, Q. Ma, K. Guo, J. Liu, et al., Xanthones from mangosteen extracts as natural chemopreventive agents: potential anticancer drug, Curr. Mol. Med. 11 (2011) 666-677.

[6] S.C. Hsieh, M.H. Huang, C.W. Cheng, et al., A-mangostin induces mitochondrial dependent apoptosis in human hepatoma SK-Hep-1 cells through inhibition of p38 MAPK pathway, Apoptosis 18 (2013) 1548-1560.

[7] Y.S. Won, J.H. Lee, S.J. Kwon, et al., A-mangostin-induced apoptosis is mediated by estrogen receptor $\alpha$ in human breast cancer cells, Food Chem. Toxicol. 28 (2014) 158-165.

[8] B.B. Hafeez, A. Mustafa, J.W. Fischer, et al., $\alpha$-Mangostin: a Dietary antioxidant derived from the pericarp of Garcinia mangostana L. inhibits pancreatic tumor growth in xenograft mouse model, Antioxid. Redox Signal., 2014, http:// dx.doi.org/10.1089/ars.2013.5212. [ahead of print].

[9] J.J. Wang, B.J. Sanderson, W. Zhang, Significant anti-invasive activities of $\alpha-$ mangostin from the mangosteen pericarp on two human skin cancer cell lines, Anticancer Res. 32 (2012) 3805-3816.

[10] A. Lentini, A. Abbruzzese, B. Provenzano, et al., Transglutaminases: key regulators of cancer metastasis, Amino Acids 44 (2013) 25-32.
[11] S. Oliverio, A. Amendola, F. Di Sano, et al., Tissue transglutaminase-dependent posttranslational modification of the retinoblastoma gene product in promonocytic cells undergoing apoptosis, Mol. Cell. Biol. 17 (1997) 60406048.

[12] C. Tabolacci, A. Lentini, P. Mattioli, et al., Antitumor properties of aloe-emodin and induction of transglutaminase 2 activity in B16-F10 melanoma cells, Life Sci. 87 (2010) 316-324.

[13] N. Ishida, D. Watanabe, Y. Akita, et al., Etretinate enhances the susceptibility of human skin squamous cell carcinoma cells to 5-aminolaevulic acid-based photodynamic therapy, Clin. Exp. Dermatol. 34 (2009) 385-389.

[14] M.S. Aguzzi, F. Facchiano, D. Ribatti, et al., A novel RGDS-analog inhibits angiogenesis in vitro and in vivo, Biochem. Biophys. Res. Commun. 321 (2004) 809-814.

[15] L. Troeberg, H. Nagase, Measurement of matrix metalloproteinase activities in the medium of cultured synoviocytes using zymography, Methods Mol. Biol. 225 (2003) 77-87.

[16] F. Facchiano, D. D’Arcangelo, A. Lentini, et al., Tissue transglutaminase activity protects from cutaneous melanoma metastatic dissemination: an in vivo study, Amino Acids 44 (2013) 53-61.

[17] V. Verdoliva, C. Senatore, M.L. Polci, et al., Differential denaturation of serum proteome reveals a significant amount of hidden information in complex mixtures of proteins, PLoS One 8 (2013) e57104.

[18] W. Huang da, B.T. Sherman, R.A. Lempicki, Systematic and integrative analysis of large gene lists using DAVID bioinformatics resources, Nat. Protoc. 4 (2009) 44-57.

[19] D. Ickowicz Schwartz, Y Gozlan, L Greenbaum, et al, Differentiationdependent photodynamic therapy regulated by porphobilinogen deaminase in B16 melanoma, Br. J. Cancer 90 (2004) 1833-1841.

[20] U.B. Hofmann, J.R. Westphal, G.N. Van Muijen, D.J. Ruiter, Matrix metalloproteinases in human melanoma, J. Invest. Dermatol. 115 (2000) 337-344.

[21] A. Lentini, C. Tabolacci, B. Provenzano, et al., Phytochemicals and proteinpolyamine conjugates by transglutaminase as chemopreventive and chemotherapeutic tools in cancer, Plant Physiol. Biochem. 48 (2010) 627-633.

[22] C. López-Alarcón, A. Denicola, Evaluating the antioxidant capacity of natural products: a review on chemical and cellular-based assays, Anal. Chim. Acta 763 (2013) 1-10.

[23] T.L. Bialy, M.J. Rothe, J.M. Grant-Kels, Dietary factors in the prevention and treatment of nonmelanoma skin cancer and melanoma, Dermatol. Surg. 28 (2002) 1143-1152.

[24] F.D. Cruz, I. Matushansky, Solid tumor differentiation therapy - is it possible?, Oncotarget 3 (2012) 559-567

[25] A.E. Tee, G.M. Marshall, P.Y. Liu, et al., Opposing effects of two tissue transglutaminase protein isoforms in neuroblastoma cell differentiation, J. Biol. Chem. 285 (2010) 3561-3567.

[26] M.A. Hamid, M.R. Sarmidi, C.S. Park, Mangosteen leaf extract increases melanogenesis in B16F1 melanoma cells by stimulating tyrosinase activity in vitro and by up-regulating tyrosinase gene expression, Int. J. Mol. Med. 29 (2012) 209-217.

[27] H.W. Ryu, S.H. Jeong, M.J. Curtis-Long, et al., Inhibition effects of mangosenone F from Garcinia mangostana on melanin formation in B16F10 Cells, J. Agric. Food Chem. 60 (2012) 8372-8378.

[28] I. Boehm, Apoptosis in physiological and pathological skin: implications for therapy, Curr. Mol. Med. 6 (2006) 375-394.

[29] R. Buscà, C. Bertolotto, J.P. Ortonne, R. Ballotti, Inhibition of the phosphatidylinositol 3-kinase/p70(S6)-kinase pathway induces B16 melanoma cell differentiation, J. Biol. Chem. 271 (1996) 31824-31830.

[30] A.K. Chakraborty, Y. Funasaka, K. Araki, et al., Evidence that the small GTPase Rab8 is involved in melanosome traffic and dendrite extension in B16 melanoma cells, Cell Tissue Res. 314 (2003) 381-388.

[31] N.H. Cho, H.S. Shim, S.Y. Rha, et al., Increased expression of matrix metalloproteinase 9 correlates with poor prognostic variables in renal cell carcinoma, Eur. Urol. 44 (2003) 560-566.

[32] J.S. Ahn, M.K. Kim, J.H. Hahn, et al., Tissue transglutaminase-induced downregulation of matrix metalloproteinase-9, Biochem. Biophys. Res. Commun. 376 (2008) 743-747.

[33] S. Beninati, M. Piacentini, The transglutaminase family: an overview: minireview article, Amino Acids 26 (2004) 367-372.

[34] J.H. Jeon, S.Y. Cho, C.W. Kim, et al., GTP is required to stabilize and display transamidation activity of transglutaminase 2, Biochem. Biophys. Res. Commun. 294 (2002) 818-822.

[35] E.A. Papakonstanti, C. Stournaras, Cell responses regulated by early reorganization of actin cytoskeleton, FEBS Lett. 582 (2008) 2120-2127.

[36] F. Facchiano, F. Deloye, F. Doussau, et al., Transglutaminase participates in the blockade of neurotransmitter release by tetanus toxin: evidence for a novel biological function, Amino Acids 39 (2010) 257-269. 